\title{
Influence of the Weight of a School Backpack on Spinal Curvature in the Sagittal Plane of Seven-Year-Old Children
}

\author{
Katarzyna Walicka-Cupryś, ${ }^{1}$ Renata Skalska-Izdebska, ${ }^{1}$ \\ Maciej Rachwal, ${ }^{1}$ and Aleksandra Truszczyńska ${ }^{2}$ \\ ${ }^{1}$ Department of Medicine, Institute of Physiotherapy, University of Rzeszów, Warszawska 26A Street, 35-205 Rzeszów, Poland \\ ${ }^{2}$ Physiotherapy Department, Józef Pitsudski University of Physical Education, Marymoncka 34, 00-968 Warsaw, Poland
}

Correspondence should be addressed to Katarzyna Walicka-Cupryś; kwcuprys@o2.pl

Received 24 April 2015; Revised 22 July 2015; Accepted 18 August 2015

Academic Editor: Frédéric Noé

Copyright (C) 2015 Katarzyna Walicka-Cupryś et al. This is an open access article distributed under the Creative Commons Attribution License, which permits unrestricted use, distribution, and reproduction in any medium, provided the original work is properly cited.

\begin{abstract}
The aim of the paper was to determine a correlation between the weight of a child's backpack, their body weight, and certain features of their body posture. Material and Methods. The study group consisted of 109 children, all aged seven years. The parameters of body posture were determined using the Zebris Ultrasonic System. Results. The number of children carrying a school backpack in accordance with recommendations was 44 subjects (40.37\%). Statistically significant changes were found in the total length of the spine $(Z=2.223, p=0.026)$ and between backpack weight and changes in the following parameters: the total length of the spine $\left(r_{s}=-0.3999, p=0.017\right)$, the length and the angle of the lumbar lordosis $\left(r_{s}=-0.3352, p=0.049\right)$, the angle of the lumbar lordosis $\left(r_{s}=-0.5065, p=0.002\right)$, and the sacral angle $\left(r_{s}=-0.4279, p=0.010\right)$. Conclusions. Wearing a backpack heavier than $10 \%$ of one's body weight can cause shallowing of the lumbar lordosis and a tendency towards a vertical position of the sacrum. Monitoring the weight of children's school backpacks and enabling them to leave books and notebooks at school would probably be beneficial in reducing the daily burden put on children's spines.
\end{abstract}

\section{Introduction}

The problem of bad posture in children and adolescents is still a current issue, frequently addressed in scientific publications [1-4]. During the early school period (seven to 10 years), body growth is relatively stable [5]. Kyphotic and balanced body postures dominate during the period of seven to eight years of age [6]. However, when the child begins to attend school, their time spent in a sitting position is extended, which can result in disorders of posturogenesis. Hence, this period is called "the first critical period of posturogenesis."

Children at this age are exposed to a number of factors that predispose them to the occurrence of bad posture. One of these factors is carrying a backpack that is too heavy for them. According to the literature, this problem affects between $40 \%$ and $70 \%$ of children in developed countries [5, 7]. Excessive backpack load causes back pain and spinal deformities in children [8-10]. The pain associated with carrying a backpack is referred to as "backpack syndrome." This syndrome includes the following factors: abnormal body posture causing headaches, fatigue, and cervical and lumbar pain $[11,12]$.

Recommendations concerning the weight of school backpacks in relation to body weight diverge depending on the organization. In 2009, the American Occupational Therapy Association (AOTA) and the American Physical Therapy Association (APTA) recommended not carrying a backpack heavier than $15 \%$ (or between $10 \%$ and $20 \%$ ) of the student's body weight; in 2012, this was changed to $10 \%$ of their body weight [13]. The American Chiropractic Association (ACA) recommended that backpack weight should not exceed 5$10 \%$ of the child's body weight. There are dangers that excessive loads pose to the maturing spine [14]. Many authors have concluded that the weight of a school backpack should not exceed $10 \%$ of the child's body weight [15], based on the fact that it can affect their spinal posture, foot shape, and gait [16-19]. However, there is still no clear information about 
TABLE 1: Basic biometric parameters characterizing the study group $(N=109)$

\begin{tabular}{lccc}
\hline & Mean & Range & SD \\
\hline Body weight $(\mathrm{kg})$ & 25.55 & $19.02-38.00$ & 4.7 \\
Body height $(\mathrm{m})$ & 1.25 & $1.13-1.39$ & 0.1 \\
\hline
\end{tabular}

SD: standard deviation.

the impact that a school backpack has on the formation of spinal curvature in the sagittal plane in school children.

The weight of backpacks carried as part of everyday activity may be related to the shape of curvatures of the spine, in particular when the activity requires taking a specific, forced posture. A child carrying a heavy backpack will tend to lean forward to balance their centre of gravity, which results in a reduction of lumbar lordosis and increased thoracic kyphosis [4]. Such a posture may become habitual and be maintained even after taking the backpack off. Thus, the authors of this study decided to look more closely into this issue.

The following hypotheses were set up: does the weight of the backpack constitute the recommended $10 \%$ of the body weight of a seven-year-old child? Does curvature of the spine change in children who carry a backpack heavier than $10 \%$ of their body weight?

The aim of the paper was to describe the relationship between the load of a child's school backpack and the occurrence of changes in the parameters of their body posture in the sagittal plane.

\section{Material and Methods}

The study was conducted at the end of the first year of primary school at Wincenty Pol Primary School in Lesko, Poland. The study group included 109 children, all aged seven years: 58 girls and 51 boys. The children had not attended a reception class before. The children in the study group were carrying their backpacks on their way to school and back and going from one classroom to another during breaks, for an average total time of 50 minutes a day. The anthropometric data of the children are summarized in Table 1.

The study was conducted after obtaining consent from the school principal, parents, and the subjects themselves and as part of a larger research project which had been approved by the local Bioethics Committee at the Faculty of Medicine, University of Rzeszów.

Inclusion criteria were as follows: only school children who were seven years of age; lack of comorbidities; only traditional school backpacks (i.e., the children's own backpacks which they carried to school every day, designed to be carried on both shoulders).

Exclusion criteria were as follows: children aged younger than seven or over eight years (e.g., children from the reception class and Year 2); lack of consent to participate in research; musculoskeletal, vision, and neurological disorders.

The parameters of body posture were determined using the Zebris Ultrasonic System with WinSpine 2.3 software. This system enables three-dimensional analysis of body posture. It consists of a sensor with a stand, the basic CMS-HS

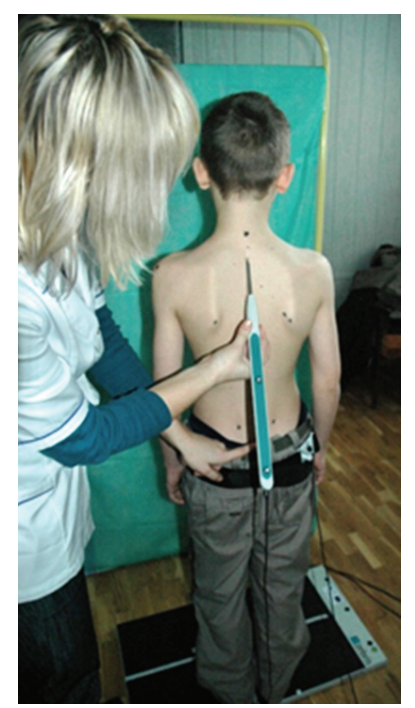

FIGURE 1: Subject's position during the examination.

unit, and a single marker with a belt to be attached to the hips of the subject. Tests using the ultrasonic spot indicator function by identifying the anatomical landmarks on the subject's skeleton, which are precisely displayed on a monitor connected to the computer [20-22]. Before the start of each test, the following anthropometric points were marked on the skin of the subject: the spinous processes of the spine, the right and left acromion, the right and left anterior superior iliac spine, the right and left iliac crest, the point of change of the thoracic spine into the lumbar spine, and the lower right and left angle of scapula (Figure 1) [23]. The tests were performed by a physiotherapist with five years of experience as an operator of the equipment and 15 years of experience in testing body posture.

The subject was positioned $80 \mathrm{~cm}$ from the receiver and equipped with the transmitter belt. The position of the subject was habitual, with the upper limbs along the trunk and the lower limbs extended in the knee and hip joints. The following instructions were given: "stand in a comfortable manner"; "do not bend your knees"; and "look straight." The children were not instructed to straighten up. When the subject corrected their body posture, the measurement was repeated so that functional defects were also noted [24, 25].

The following parameters of the subjects' posture were measured: ThS ( $\mathrm{mm})$ : total length of the spine; THL $(\mathrm{mm})$ : length of the thoracic spine; LS (mm): length of the lumbar spine; KKP (degrees): thoracic kyphosis angle, calculated from the intersection of the tangents extending between the spinous processes of Th1 and Th2 and Th1l and Th12 (Figure 2); KKL (degrees): angle of lumbar lordosis, calculated from the intersection of the tangents extending between the spinous processes of L1 and L2 and L5 and S1 (Figure 2); TTI (degrees): total angle of anterior trunk inclination (Figure 3); and SCR (degrees): sacral angle in the study group (sacral angle is defined as the angle between the line connecting the spinous processes S1 and S3 and the frontal plane) (Figure 2). 


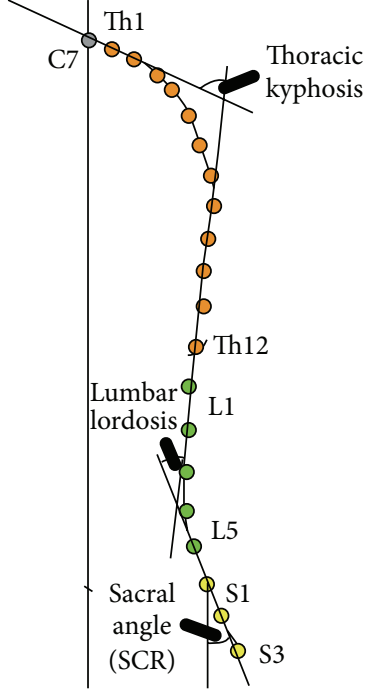

Figure 2: Analysed parameters.

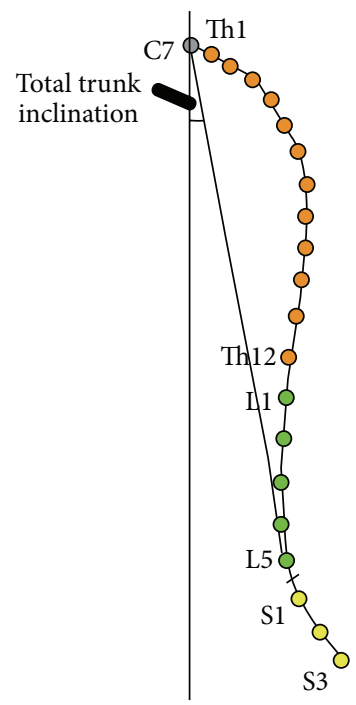

FIgURE 3: Analysed parameters.

As a next step, the child's body height, body weight, and school backpack weight (along with its contents) were measured. These measurements were made using the seca 213 portable stadiometer height rod (digital scale with $0.1 \mathrm{~kg}$ accuracy). The group was examined in the morning, during school hours, that is, during an ordinary school day according to the school timetable.

\section{Statistical Analysis}

The differences in posture between the groups (Group 1, weight of backpack less than $10 \%$ of child's body weight, and Group 2, backpack heavier than 10\% of child's body weight) were determined using the Mann-Whitney $U$ test, which is equivalent to nonparametric variance. The correlation between the weight of the backpack carried by the child every
TABLE 2: The weight of the school backpacks carried by the subjects.

\begin{tabular}{lccc}
\hline & Mean & Range & SD \\
\hline Weight of school backpack $(\mathrm{kg})$ & 2.87 & $1.64-4.10$ & 0.50 \\
\hline $\begin{array}{l}\text { Weight of school backpack in } \\
\text { relation to child's body weight (\%) }\end{array}$ & 10.90 & $6.78-17.47$ & 3.14 \\
\hline
\end{tabular}

SD: standard deviation.

day and the parameters of posture in the sagittal plane was investigated using Spearman's correlation coefficient. The results were considered statistically significant at $p<0.05$. The obtained results were analysed statistically using STATISTICA 9.0.

\section{Results}

The number of children carrying school backpacks in accordance with recommendations (i.e., weighing less than $10 \%$ of their body weight) was 44 subjects $(40.37 \%)$.

The weight analysis of the school backpacks and their relation to the body weight of the children showed that the weight of the carried load often exceeded the $10 \%$ recommended in the literature. Detailed results are shown in Table 2 .

The parameters describing the spinal shapes of the two groups (Group 1, with backpacks weighing less than $10 \%$ of the children's body weight, and Group 2, with backpacks heavier than $10 \%$ of the children's body weight) are shown in Table 3 . The only statistically significant differences between the groups were observed for the total length of the spine $(p=0.026)$.

A statistically significant relationship was revealed between the load of the school backpack and the total length of the spine, the length of the lumbar lordosis, the lumbar lordosis angle, and the angle of sacrum inclination. With the increase in the weight of the backpack, the measured parameters decreased. No statistically significant differences were found for the following parameters: THL (length of the thoracic spine), KKP (angle of thoracic kyphosis), and TTI (total angle of anterior trunk inclination). Details are shown in Table 4.

\section{Discussion}

The issue of school backpack load is still a valid one [26, 27]. The new conditions under which children begin to undertake their education may contribute to the emergence or worsening of bad posture. Children's spontaneous physical activity is restricted during the mandatory school age. Their body posture is influenced not only by the restricted room for movement but also by carrying external loads. Overloaded school backpacks can be a threat to the correct development of posture [28].

Children usually carry their backpacks for a relatively short period every day. Nevertheless, the relationship between backpack load and spine shape in the sagittal plane observed in the study arouses a certain interest. In our study, the school backpacks filled with books weighed on average 
TABLE 3: Summary of the parameters characterizing the children's body postures.

\begin{tabular}{lcccccccc}
\hline & \multicolumn{3}{c}{ Backpacks lighter than 10\% of body weight } & \multicolumn{3}{c}{ Backpacks heavier than 10\% of body weight } & \multicolumn{2}{c}{ Mann-Whitney $U$ test } \\
& Mean & Range & SD & Mean & Range & SD & $Z$ & $p$ \\
\hline ThS (mm) & 375.4 & $350.3-400.5$ & 25.1 & 357.0 & $320.7-393.3$ & 36.3 & 2.223 \\
THL (mm) & 230.4 & $212.5-248.3$ & 17.9 & 223.4 & $203.7-243.1$ & 19.7 & 1.252 \\
LS (mm) & 107.0 & $90.6-123.4$ & 16.4 & 98.4 & $77.7-119.1$ & 20.7 & 1.454 & 0.026 \\
KKP (deg.) & 47.4 & $33.8-61.0$ & 13.6 & 43.8 & $31.1-56.5$ & 12.7 & 1.414 & 0.146 \\
KKL (deg.) & 26.6 & $12.3-40.9$ & 14.3 & 23.9 & $12.2-35.6$ & 11.7 & 1.112 & 0.266 \\
TTI (deg.) & 4.2 & $2.3-6.1$ & 1.9 & 3.4 & $1.4-5.4$ & 2.0 & 1.345 & 0.179 \\
SCR (deg.) & 24.5 & $14.7-34.3$ & 9.8 & 19.5 & $9.3-29.7$ & 10.2 & 1.927 & 0.054 \\
\hline
\end{tabular}

ThS (mm): total length of the spine.

THL (mm): length of the thoracic spine.

LS (mm): length of the lumbar spine.

KKP (degrees): thoracic kyphosis angle, calculated from the intersection of the tangents extending between the spinous processes of Th1 and Th2 and Thll and Th12.

KKL (degrees): angle of lumbar lordosis, calculated from the intersection of the tangents extending between the spinous processes of L1 and L2 and L5 and S1. TTI (degrees): total angle of anterior trunk inclination.

SCR (degrees): sacral angle in the study group (sacral angle is defined as the angle between the line connecting the spinous processes S1 and S3 and the frontal plane).

SD: standard deviation; $Z$ : Mann-Whitney $U$ test; $p$ : significance level.

TABLE 4: The relationship between the child's school backpack load and the occurrence of changes in the parameters of the child's body posture in the sagittal plane, using Spearman's correlation coefficient.

\begin{tabular}{|c|c|c|}
\hline $\begin{array}{l}\text { Anthropometric } \\
\text { parameters }\end{array}$ & $r_{s}, p$ (value) & Interpretation \\
\hline ThS & $-0.3999,(0.017)$ & $\begin{array}{l}\text { The heavier the backpack, the } \\
\text { lower the total length of the } \\
\text { spine }\end{array}$ \\
\hline THL & $-0.2313,(0.181)$ & Not significant \\
\hline LS & $-0.3352,(0.049)$ & $\begin{array}{l}\text { The heavier the backpack, the } \\
\text { lower the length of the lumbar } \\
\text { lordosis }\end{array}$ \\
\hline KKP & $-0.2695,(0.117)$ & Not significant \\
\hline KKL & $-0.5065,(0.002)$ & $\begin{array}{l}\text { The heavier the backpack, the } \\
\text { smaller the lumbar lordosis } \\
\text { angle }\end{array}$ \\
\hline TTI & $-0.0537,(0.759)$ & Not significant \\
\hline SCR & $-0.4279,(0.010)$ & $\begin{array}{l}\text { The heavier the backpack, the } \\
\text { smaller the sacral angle }\end{array}$ \\
\hline
\end{tabular}

ThS (mm): total length of the spine.

THL (mm): length of the thoracic spine.

LS (mm): length of the lumbar spine.

KKP (degrees): thoracic kyphosis angle.

KKL (degrees): lumbar lordosis angle.

TTI (degrees): total angle of anterior trunk inclination.

SCR (degrees): sacral angle.

$r_{s}$ : Spearman's correlation coefficient.

$2.87 \mathrm{~kg}$. The backpacks were weighed once during the study, assuming that the backpack weight would be similar every day, based on the number of daily lessons; these data correspond with the findings of other researchers. Nevertheless, the issue should be taken into account when analysing the obtained results. It has already been mentioned that the results are consistent with the results of other researchers, for example, those of Al-Hazzaa regarding similarly aged children. In this study, the mean weight of the backpack was $2.77 \mathrm{~kg}$, but higher values were accepted for school backpack weight as a percentage of mean body weight (12.5\%) compared to in our study (10.9\%) [29]. In other parts of the world, higher values have also been recorded, such as $13.2 \%$ [30] and $12 \%$ [31]. Our study also confirmed this disturbing phenomenon: during the tests carried out in Year 1, the overload of school backpacks was found among $60 \%$ of the respondents.

A study by Kułaga and Grajda found that a backpack weight exceeding $10-15 \%$ of the child's body weight forces the child to compensate for the excessive load by tilting their torso forward. However, according to the authors, a greater impact on the children's posture was produced by the wrong position of the body, rather than the weight of the backpack [24]. Pau et al. found that an external load increased the distribution of asymmetries in foot pressure forces on the ground. In addition, carrying a school backpack in the wrong way was found to exacerbate existing disorders [32].

Relationships between a child's school backpack load and the total length of their spine, the size of their lumbar lordosis, and their sacrum inclination were all found in our study. When the school backpack weight was higher, greater decrease of the lumbar lordosis was observed, and the sacrum inclination was smaller. Such a situation may lead to a reduction in the natural curvature of the lumbar spine and related adverse consequences, such as reduced amortization properties of the spine, and asymmetric loading of intervertebral discs, which can lead to overloading and degenerative changes in the spine.

There was no relationship observed between backpack load and the length of the thoracic spine, the angle of thoracic kyphosis, or the anterior inclination of the trunk. The lack of correlation with the angle of thoracic kyphosis in our study may be due to the fact that over $40 \%$ of the children 
wore backpacks according to the standard, that is, weighing less than $10 \%$ of the weight of the child. The habitual posture during rest and learning should be controlled, and the weight of the school backpacks should also be checked by parents and representatives of the educational institutions. Continuous monitoring and systematic screening tests to detect abnormalities in body posture are also justified.

\section{The Value of the Research}

Studies evaluating the incidence of abnormal behaviour, such as children wearing heavy backpacks and the relationship between this and their posture, are important in the prevention of back pain. The observed reduction and shortening of the lumbar spine as the weight of the carried backpack increases may indicate a primary cause of subsequent future overloading and degenerative changes in the spine. It can also help explain the occurrence of lower back pain in school children, discussed widely in the literature [33-35]. The unambiguous evidence showing that the weight of school backpacks is related to the shape of spine curvature will allow schools to include compensation exercises in physical education curricula, ensuring optimum physical development by encouraging balanced and spontaneous physical activity during the day (e.g., as recreation activities). Thus, opportunities to help protect the spine will be created.

\section{Limitations of the Research}

The weight of the backpacks without content (which would have indicated the actual weight of the school books and notebooks) was not examined, as the weight was checked only once. In addition, the study was not a longitudinal study conducted over a longer period, for example, at the beginning and the end of the school year.

\section{Conclusions}

(i) Wearing a backpack heavier than $10 \%$ of one's body weight can cause shallowing of the lumbar lordosis and a tendency towards a vertical position of the sacrum.

(ii) Monitoring the weight of children's school backpacks by parents and teachers, as well as children themselves, and enabling them to leave books and notebooks at school would probably be beneficial in reducing the daily burden put on children's spines.

\section{Conflict of Interests}

The authors declare that there is no conflict of interests regarding the publication of this paper. The study was funded using the authors' own resources.

\section{References}

[1] J. DrzaŁ-Grabiec and S. Snela, "The influence of rural environment on body posture," Annals of Agricultural and Environmental Medicine, vol. 19, no. 4, pp. 846-850, 2012.
[2] J. Drzał-Grabiec, K. Walicka-Cupryś, and A. Truszczyńska, "The influence of applied research methods on the frequency of the appearance of abnormal spinal curvatures," Advances in Rehabilitation, vol. 4, pp. 41-46, 2013.

[3] J. Paušić, Ž. Pedišić, and D. Dizdar, "Reliability of a photographic method for assessing standing posture of elementary school students," Journal of Manipulative and Physiological Therapeutics, vol. 33, no. 6, pp. 425-431, 2010.

[4] J. Drzał-Grabiec, A. Truszczyńska, J. Rykała, M. Rachwał, S. Snela, and J. Podgórska, "Effect of asymmetrical backpack load on spinal curvature in school children," Work, vol. 51, no. 2, pp. 383-388, 2015.

[5] E. Kellis and M. Emmanouilidou, "The effects of age and gender on the weight and use of schoolbags," Pediatric Physical Therapy, vol. 22, no. 1, pp. 17-25, 2010.

[6] K. Barczyk, T. Skolimowski, J. Anwajler, and D. ChameraBilińska, "Somatic features and parameters of anterior-posterior spinal curvature in 7-year-olds with particular posture types," Ortopedia, Traumatologia, Rehabilitacja, vol. 7, no. 5, pp. 555562, 2005.

[7] S. Dockrell, C. Simms, and C. Blake, "Schoolbag carriage and schoolbag-related musculoskeletal discomfort among primary school children," Applied Ergonomics, vol. 51, pp. 281-290, 2015.

[8] M. J. Moore, G. L. White, and D. L. Moore, "Association of relative backpack weight with reported pain, pain sites, medical utilization, and lost school time in children and adolescents," Journal of School Health, vol. 77, no. 5, pp. 232-239, 2007.

[9] Y. Hong, D. T.-P. Fong, and J. X. Li, "The effect of school bag design and load on spinal posture during stair use by children," Ergonomics, vol. 54, no. 12, pp. 1207-1213, 2011.

[10] N. R. Talbott, A. Bhattacharya, K. G. Davis, R. Shukla, and L. Levin, "School backpacks: it's more than just a weight problem," Work, vol. 34, no. 4, pp. 481-494, 2009.

[11] W. G. Mackenzie, J. S. Sampath, R. W. Kruse, and G. J. Sheir-Neiss, "Backpacks in children," Clinical Orthopaedics and Related Research, vol. 409, pp. 78-84, 2003.

[12] D. H. K. Chow, Z. Y. Ou, X. G. Wang, and A. Lai, "Short-term effects of backpack load placement on spine deformation and repositioning error in schoolchildren," Ergonomics, vol. 53, no. 1, pp. 56-64, 2010.

[13] R. Avantika and A. Shalini, "Back problems due to heavy backpacks in school children," IOSR Journal of Humanities and Social Science, vol. 10, no. 6, pp. 22-26, 2013.

[14] M. J. Sanders, "Ergonomics of child care," in Ergonomics and the Management of Musculoskeletal Disorders, M. J. Sanders, Ed., pp. 405-418, Elsevier Health Sciences, 2nd edition, 2004.

[15] S. Goodgold, M. Corcoran, D. Gamache, J. Gillis, J. Guerin, and J. Q. Coyle, "Backpack use in children," Pediatric Physical Therapy, vol. 14, no. 3, pp. 122-131, 2002.

[16] F. Kistner, I. Fiebert, K. Roach, and J. Moore, "Postural compensations and subjective complaints due to backpack loads and wear time in schoolchildren," Pediatric Physical Therapy, vol. 25, no. 1, pp. 15-24, 2013.

[17] D. H. K. Chow, K. T. Y. Leung, and A. D. Holmes, "Changes in spinal curvature and proprioception of schoolboys carrying different weights of backpack," Ergonomics, vol. 50, no. 12, pp. 2148-2156, 2007.

[18] J. Drzał-Grabiec, S. Snela, M. Rachwał, J. Rykała, and J. Podgórska, "Effects of carrying a backpack in a symmetrical manner on the shape of the feet," Ergonomics, vol. 56, no. 10, pp. 1577-1583, 2013. 
[19] Y. Hong and C.-K. Cheung, "Gait and posture responses to backpack load during level walking in children," Gait and Posture, vol. 17, no. 1, pp. 28-33, 2003.

[20] W. Rusek, T. Pop, J. Glista, and J. Skrzypiec, "Assessment of student's body posture with the use of ZEBRIS system," Medical Journal of Rzeszow University and National Institute of Medicines in Warsaw, no. 3, pp. 277-288, 2010.

[21] M. Küster, "Jugendliche in der pubertät: motorisches leistungsvermögen, rumpfkraft und wirbelsäulenparameter in abhängigkeit von sport- und medienkonsum," Österreichisches Journal für Sportmedizin, vol. 34, no. 1, pp. 10-17, 2004.

[22] WinSpine 2.3 for Windows, Operating Instructions of Zebris Pointer, Zebris Medical GmbH, Allgau, Germany, 2008.

[23] K. Walicka-Cupryś and A. Kużdżał, "Objectified criteria for the assessment of body posture using an ultrasonic system Zebris," Manual Medicine, vol. 17, no. 1, pp. 19-23, 2013.

[24] J. Drzał-Grabiec, S. Snela, J. Rykała, J. Podgórska, and A. Truszczyńska, "The influence of elongation exercises on the anterior-posterior spine curvatures," Biomedical Human Kinetics, vol. 6, no. 1, 2014.

[25] J. Glista, T. Pop, A. Weres et al., "Change in anthropometric parameters of the posture of students of physiotherapy after three years of professional training," BioMed Research International, vol. 2014, Article ID 719837, 9 pages, 2014.

[26] M. Dolphens, B. Cagnie, P. Coorevits et al., "Sagittal standing posture and its association with spinal pain: a school-based epidemiological study of 1196 flemish adolescents before age at peak height velocity," Spine, vol. 37, no. 19, pp. 1657-1666, 2012.

[27] F. Kistner, I. Fiebert, and K. Roach, "Effect of backpack load carriage on cervical posture in primary schoolchildren," Work, vol. 34, no. 4, pp. 481-494, 2009.

[28] H. M. Brackley, J. M. Stevenson, and J. C. Selinger, "Effect of backpack load placement on posture and spinal curvature in prepubescent children," Work, vol. 32, no. 3, pp. 351-360, 2009.

[29] H. M. Al-Hazzaa, "School backpack how much load Saudi school bags carry on their shoulder?" Saudi Madical Journal, vol. 27, no. 10, pp. 1567-1571, 2006.

[30] J. K. Whittfield, S. J. Legg, and D. I. Hedderley, “The weight and use of schoolbags in New Zealand secondary schools," Ergonomics, vol. 44, no. 9, pp. 819-824, 2001.

[31] G. Casey and S. Dockrell, "A pilot study of the weight of school bags carried by 10-year old children," Physiotherapy Ireland, vol. 17, no. 2, pp. 17-21, 1996.

[32] M. Pau, S. Mandaresu, B. Leban, and M. A. Nussbaum, "Shortterm effects of backpack carriage on plantar pressure and gait in schoolchildren," Journal of Electromyography and Kinesiology, vol. 25, no. 2, pp. 406-412, 2015.

[33] C. Jackson, K. McLaughlin, and B. Teti, "Back pain in children: a holistic approach to diagnosis and management," Journal of Pediatric Health Care, vol. 25, no. 5, pp. 284-293, 2011.

[34] J.-C. Bernard, R. Bard, A. Pujol et al., "Muscle assessment in healthy teenagers: comparison with teenagers with low back pain," Annales de Réadaptation et de Médecine Physique, vol. 51, no. 4, pp. 274-283, 2008.

[35] F. C. Trevelyan and S. J. Legg, "Back pain in school childrenwhere to from here?" Applied Ergonomics, vol. 37, no. 1, pp. 45$54,2006$. 


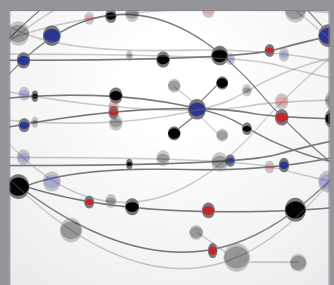

The Scientific World Journal
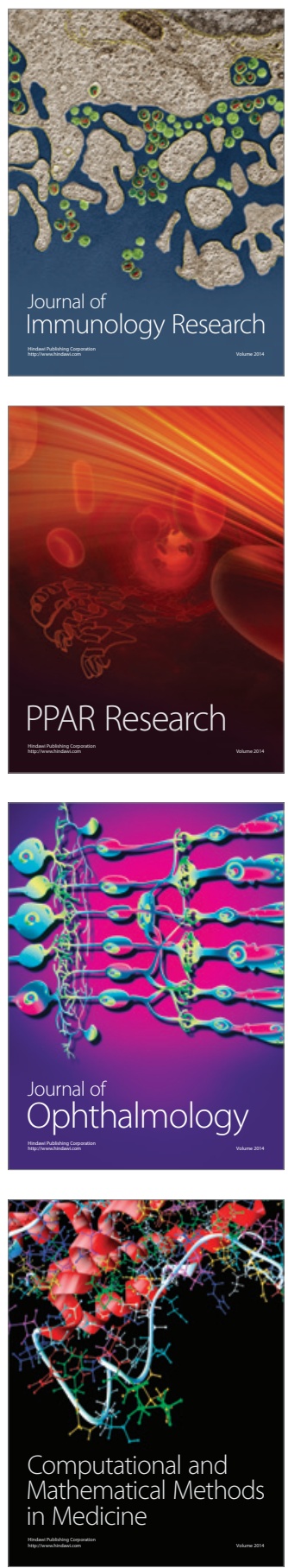

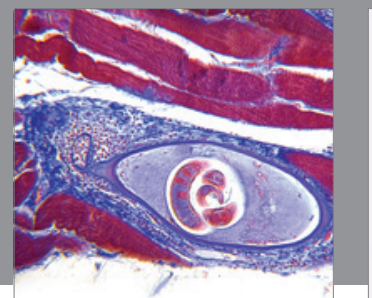

Gastroenterology

Research and Practice
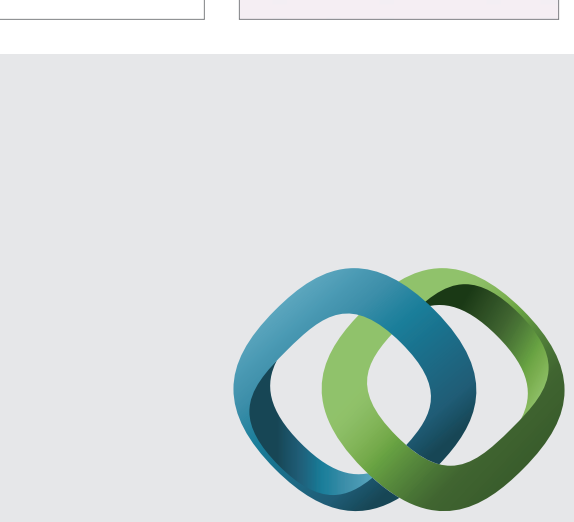

\section{Hindawi}

Submit your manuscripts at

http://www.hindawi.com
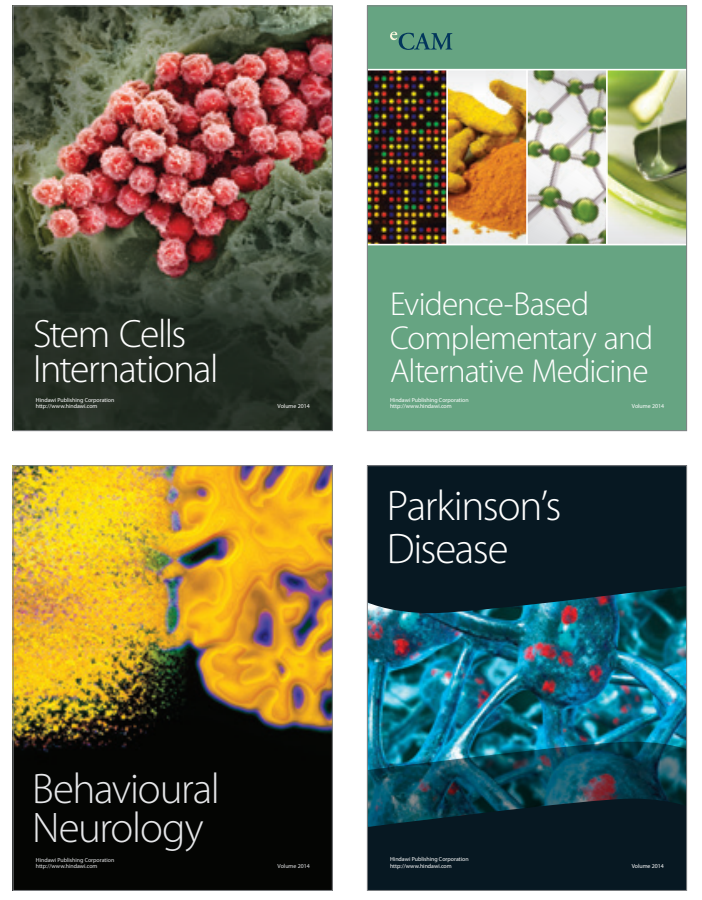
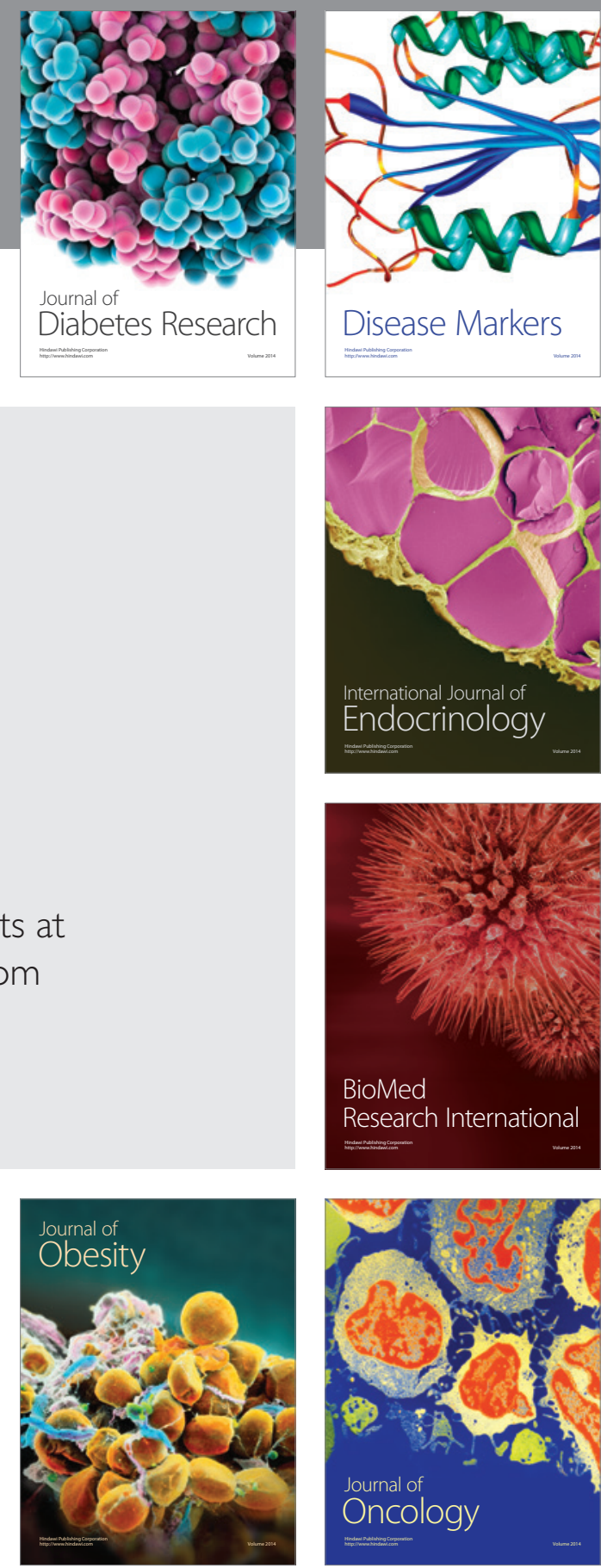

Disease Markers
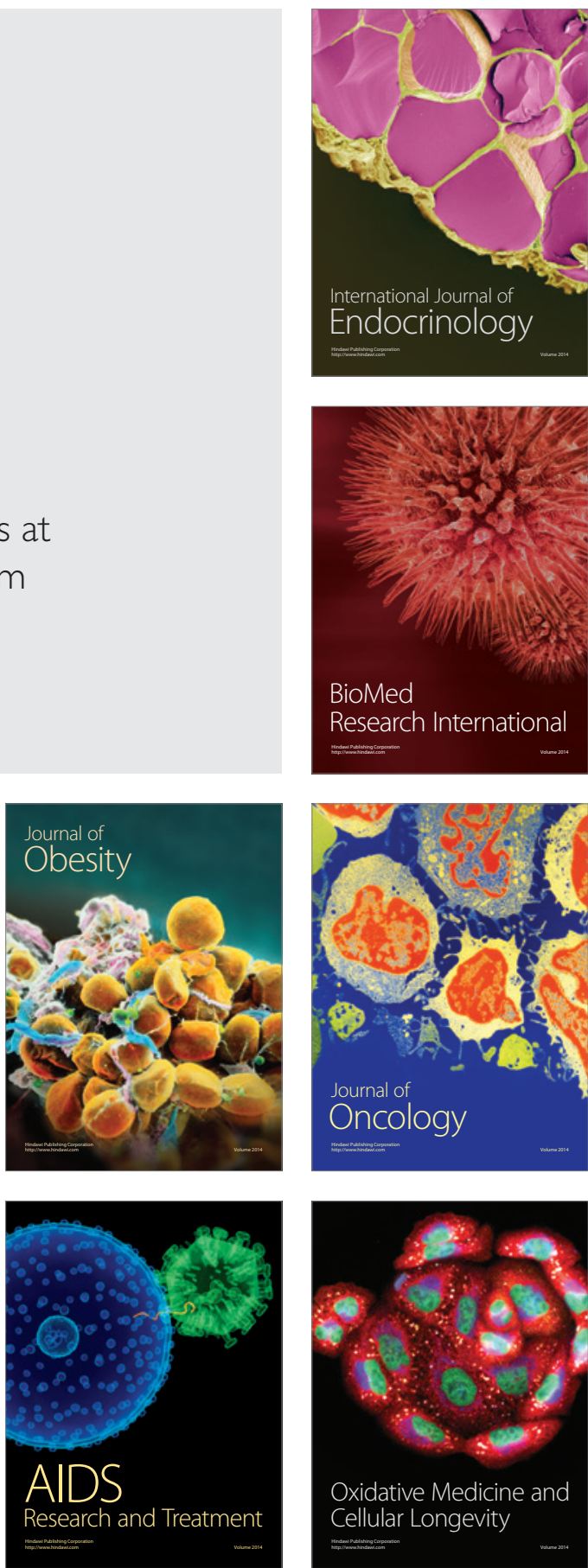